\title{
Políticas e práticas da história escolar no ensino médio do Brasil: a interdisciplinaridade em debate
}

\author{
Margarida Maria Dias de Oliveira*
}

Maria Inês Sucupira Stamatto**

Itamar Freitas ${ }^{* * *}$

\section{Resumo}

A questão da interdisciplinaridade é uma nova e específica demanda que se coloca para a formação de professores. Como, então, efetivá-la nas áreas de História e de Geografia, quando as mesmas são confundidas com os antigos Estudos Sociais? Este texto pretende narrar a introdução da proposta de Estudos Sociais, intermediada pela Escola Nova, e a sua posterior permanência na educação brasileira durante o século XX. Em seguida, apresenta e discute a abordagem da interdisciplinaridade nos documentos que orientam o Ensino Médio no Brasil entre 1998 e 2013. Para tanto, analisa a bibliografia e os documentos oficiais que referenciam a questáo e, a partir deles, propóe algumas hipóteses para a táo conflituosa discussão sobre a inserção da interdisciplinaridade na educação básica, embora amplamente defendida na academia.

Palavras-chave: Ensino de História. Interdisciplinaridade. Ensino Médio.

*Doutora em História pela Universidade Federal de Pernambuco (UFPE). Professora Associada I do Departamento de História da Universidade Federal do Rio Grande do Norte (UFRN).

** Doutora em História pela Études des Sociétés Latinoaméricaines - Universite de Paris III (Sorbonne-Nouvelle). Professora Associada IV do Departamento Fundamentos e Políticas da Educaçáo da Universidade Federal do Rio Grande do Norte (UFRN).

*** Doutor em Educação pela Pontifícia Universidade Católica de São Paulo (PUC/SP). Doutorando em História pelo Programa de Pós-Graduação em História da Universidade Federal do Rio Grande do Sul (UFRGS). Professor do Departamento de História da Universidade de Brasília (UNB). 


\section{O estigma dos Estudos Sociais e a Interdisciplinaridade}

Que novas e específicas demandas se colocam para a formação de professores, na emergência das mudanças realizadas no Ensino Médio? A questão da interdisciplinaridade é uma delas. É tema fundamental na formação docente em virtude de ter-se tornado princípio orientador na atual legislação. Contudo, o que fazer para torná-la efetiva no interior da escola?

Em geral, o professor de História do Ensino Básico não aceita tranquilamente a proposição de interdisciplinaridade quando a associa aos Estudos Sociais. Evoca o uso desta matéria na reforma educacional realizada no período da Ditadura Militar, quando a disciplina História, entre outras, sofreu drástica redução em sua carga, abrindo espaço, na grade curricular, para matérias de cunho ufanista (apologistas do governo recém-instalado) como Organização Social e Política Brasileira (OSPB) e Moral e Cívica. Além disso, no contexto pós-1964, o ensino de História e de Geografia foi cerceado em sua função reflexiva e crítica, reforçando a ideia de uma história que resultaria da sucessão de fatos e heróis.

Com o estabelecimento das licenciaturas curtas, através do Decreto-lei no 547, de 18 de abril de 1969, entre as quais a licenciatura em Estudos Sociais, aligeirava-se a formação do professor em detrimento do aprendizado específico de uma área de atuação profissional (BRASIL, 1969). Ao formar-se, o aluno não estava habilitado a lecionar História tampouco Geografia. Não dominava os conhecimentos básicos dos fazeres histórico ou geográfico.

Essa experiência se encerra em 1982, quando foram revogadas as licenciaturas curtas, OSPB. e Moral e Cívica, possibilitando o currículo em formato de disciplinas e não mais em áreas, estabelecendo as matérias autônomas de História e de Geografia.

Esses acontecimentos distam de nós há mais de duas décadas. Contudo, seria possível encontrar docentes, em pleno século XXI, que ainda confundam interdisciplinaridade e Estudos Sociais?

A proposta de Estudos Sociais é de fato, bem mais antiga do que se imagina, é anterior a 1964, e desde o início, não foi consensual quando projetos eram discutidos para sua implementação, como o Projeto n ${ }^{\circ} 4.132$, de 1954, que alterava a Lei Orgânica do Ensino Secundário. Guy de Hollanda (1957, p. 246) comenta sobre os debates ocorridos nesta ocasiáo, afirmando que havia "entre a maioria dos professores brasileiros de História e de Geografia 
uma ojeriza em relação aos Estudos Sociais, de cunho norte-americano”. Nos Estados Unidos, os Estudos Sociais foram adotados desde 1916 nos currículos da escola elementar e secundária (JOHNSON, 1938; OEA, 1940).

Desde o início do século XX esta proposta aparece no Brasil através do movimento escolanovista, que já vinha se estruturando desde o final do século XIX na Europa e Estados Unidos. "Há acordo para fixar o início do movimento na fundação - em Abbots-holme, por C. Reddie, em 1889 - da primeira New School britânica" (ZANTEN, 2011, p. 243). As escolas novas surgem em locais diferenciados, primeiramente na zona rural, e se difundem pela Europa, como a École des Roches, fundada em 1899; o dos New Ideals in Education de B. Ensor, em 1914; e o de L'École rénovée de F. Ferrer, em 1901 (ZANTEN, 2011).

No Brasil, o movimento renovador surge ligado principalmente à escola primária, portando inclusive a proposta de Estudos Sociais, especialmente nos planejamentos didáticos e na formação de professor. Autores vinculados à Escola Nova como John Dewey (1859-1952), Maria Montessori (1870-1952), Ovídio Decroly (1871-1932), William Kilpatrik (1871-1965), Adolfo Ferrière (18791961), Edouard Claparéde (1873-1940), tornaram-se conhecidos no Brasil, sobretudo a partir de 1930, quando Lourenço Filho (2002, p. 11) publica o livro Introdução ao Estudo da Escola Nova, "que viria a constituir uma espécie de 'Bíblia' para os educadores brasileiros". A partir de então, introduz-se as Unidades de trabalho. Os planos escolares deveriam contemplar unidades, ou seja, não poderiam mais ser uma lista de conteúdos ou de liçóes, devendo estar agrupados em uma unidade com um tema comum. Aos poucos, a prática se generalizou em todos os níveis de ensino, inclusive no superior.

Outras publicaçôes visando à formação docente foram divulgadas no Brasil, como, por exemplo, Novos caminhos e novos fins ( $2^{\mathrm{a}}$ ed. 1934), de Fernando de Azevedo; Educação Progressiva (4a ed. 1954), de Anísio Teixeira; Sociologia Educacional (2a ed. 1940), de Delgado de Carvalho; a Didática da Escola Nova, de A. M. Aguayo ( $9^{a}$ ed. em 1954). Inclusive houve uma revista, com duraçáo de seis números, denominada Escola Nova, primeira ediçâo em outubro de 1930, publicada em São Paulo por Lourenço Filho "para um Brasil novo, uma escola nova" procurando levar aos professores os princípios da escola renovada (MATE, 2011).

Também aparecem manuais escolares, denominados Estudos Sociais, para uso nas escolas. Exemplo da presença dos Estudos Sociais nas escolas brasileiras, agregando temas de estudo que envolviam as ciências humanas e naturais, é a coleção "Ciências Sociais", de Ariosto Espinheira, utilizada nas escolas ao longo 
das décadas de 1930 e 1940. Essa foi uma coleção, publicada pelos editores $J$. $R$. de Oliveira \& Cia., no Rio de Janeiro, em 1935, fundamentada no Programa de Ciências Sociais do Departamento de Educaçâo do Distrito Federal, que era voltada para alunos de $1^{\circ}$ a $5^{\circ}$ ano do curso primário. $\mathrm{O}$ volume I da coleçấo estava na sua $9^{a}$ edição no ano de 1939 e o volume II estava na $16^{a}$ edição no ano de 1941 (FERNANDES, 2009).

Oficialmente, porém, foram as diversas reformas no ensino empreendidas na década de 1920 nos estados brasileiros que buscaram efetivar o ideário escolanovista. Entre as mais conhecidas, pode-se elencar a de Sampaio Dória, em São Paulo, em 1920; a de Lourenço Filho, no Ceará, em 1922; a de Carneiro Leão, no Distrito Federal, em 1922; a de Francisco Campos, em Minas Gerais, em 1927; a de Carneiro Leão, em Pernambuco, em 1928; a de Fernando de Azevedo, novamente no Distrito Federal, em 1928; e a de Anísio Teixeira, no mesmo ano, na Bahia. Autores expoentes da Escola Nova foram referenciados em algumas dessas reformas.

Ainda na década de 1930, no Rio Grande do Sul, a escola primária prescrevia conteúdos de Estudos Sociais e de Estudos Naturais. A primeira matéria somava conhecimentos de História e de Geografia, e a segunda tratava de saberes elementares do que hoje conhecemos como Física, Química e Biologia (CORREIA FILHO, 1953). Contudo, foi na gestão de Anísio Teixeira na Secretaria Municipal de Educação da cidade do Rio de Janeiro, de 1931 a 1935, que os Estudos Sociais foram introduzidos com grande repercussão, já que se tratava do sistema público do Distrito Federal,

Sob sua inspiração direta [de Anísio Teixeira], foi publicado, em 1934, um Programa de Ciências Sociais para a escola elementar, que teve várias edições sucessivas até 1955. Reapareceu novamente, agora sob o título de Estudos Sociais na Escola Elementar, nos anos sessenta, quando, com pequenas modificaçóes, foi incorporado à Biblioteca do Professor Brasileiro, no Programa de Emergência do Ministério da Educação e Cultura, à frente do qual, encontrava-se, então, o professor Darcy Ribeiro. (NADAI, 1988, p. 13).

Oliveira e Monteiro (1992, p. 6) explicam as semelhanças e diferenças entre Estudos Sociais e Ciências Sociais, considerando que esta última seria 
formada pela Economia, Geografia Humana, História, Política, Sociologia e Antropologia Cultural, e que "ambas tratariam das relaçốes humanas". Porém, os Estudos Sociais seriam abordados "em nível da infância e adolescência", com conteúdo que trataria "diretamente das relaçôes humanas, selecionado das Ciências Sociais e desenvolvido em nível escolar, ou seja, em nível da clientela"; já as Ciências Sociais estariam no "plano do adulto, designação dada aos estudos e pesquisas de materiais feitos em nível elevado", que buscariam "o conhecimento do ser humano e suas relaçóes sociais" implicando em pesquisa, descoberta, experimentação (OLIVEIRA; MONTEIRO, 1992, p .6).

No Programa de 1934 e nos manuais escolares de Estudos Sociais, temas como o sol, as plantas, os animais, a família, casa, escola e rua são sugeridos. Nesse sentido, pode-se perceber claramente a influência do programa proposto por Ovídio Decroly:

O estudo do meio pode se resumir nos seguintes itens:
a) A criança e a família.
b) A criança e a escola.
c) A criança e a sociedade.
d) A criança e o mundo animal.
e) A criança e o mundo vegetal.
f) A criança e a terra, a água, o ar e as rochas.
g) A criança e o sol, a lua e as estrelas. (AGUAYO, 1954, p. 122).

Assim, é fácil constatar que os Estudos Sociais nascem dentro da proposta escolanovista e perduram durante o século XX, no país, não apenas no Programa de 1934, como em outros momentos em que a legislação facultou esta proposta, como é o caso da Lei ${ }^{\circ}$ 4.024, de 20 de dezembro de 61, quando vários estados estabeleceram em seus currículos a área de Estudos Sociais (BRASIL, 1961).

Durante o século XX, no Brasil, muitas proposiçôes diferenciadas advindas do movimento escolanovista foram implementadas, experimentadas, difundidas, incorporadas ao sistema educacional e nas salas de aula do país, entre elas a dos Estudos Sociais, método por projeto, globalização da aprendizagem, método de complexos ou centros de interesse, método de contos, método de problemas, entre outros. 
Entretanto, em muitos casos, estes métodos foram abandonados, permanecendo algumas experiências localizadas em uma escola, cidade ou estado, ou ainda, em um determinado período. Em outros casos, foram transformados, adaptando-se a novas realidades. Seriam entáo casos típicos de Estudos Sociais ou de interdisciplinaridade?

Para atender esta área, os livros didáticos continuaram a ser utilizados até o início do século XXI, quando o PNLD 2000/2001 avaliou e aprovou as seguintes obras de Estudos Sociais para as escolas do ensino fundamental: "Você e sua comunidade - Estudos Sociais", de Maria da Assunção de Marco Teixeira e Mariângela de Marco Fonseca; "A escola, a casa - Estudos Sociais", para a $1^{\text {a }}$ série, e "Os arredores da escola, o bairro", para a 2a série, ambos de Aracy do Rego Antunes, Maria de Lourdes Araújo Trindade e Tomoko Iyda Paganelli; "Eu não sou uma bola - Integração Social", de Jorge Geraldo Brito; "Eu: meu espaço, minha vida - Estudos Sociais", de Marly Martins Perissé; "Estudos Sociais - viajando no tempo e no espaço", de Marly Martins Perissé e Márcia Santos; "Um Jeito de aprender Estudos Sociais"; "Gente da Escola, Escola da gente - Estudos Sociais", de Marília Bacelar, Eliana Caboclo, José Silveira e Irene de Barcelos; "Bom Tempo Estudos Sociais", de Marilze Lopes Peixoto e Stella Maria Zattar; "Viva vida - Estudos Sociais", de Marta Ramos de Azevedo; "O município em debate - Estudos Sociais", de José Roberto Martins Ferreira; "Amazonas - Estudos Sociais", de Valéria Martins Lippi; "Meu estado São Paulo Estudos Sociais", de Geraldo Sales, Marlene Ordoñez e Celso Antunes; e "Conhecendo o Tocantins - Estudos Sociais", de Janete Lins Rodrigues (Coord.) (GUIA, 2000). Neste mesmo PNLD, aceitavam-se também as obras que partilhavam, no mesmo volume, os componentes curriculares de História e Geografia.

Diante dessas informações sobre a permanência dos Estudos Sociais na educação brasileira e, ainda, considerando o nada rigoroso emprego do termo "interdisciplinaridade" entre nós (ARÉNILLA; GOSSOT; ROLLAND, 2001), pensamos que a questão inicial é bastante pertinente: os professores podem confundir Estudos Sociais e Interdisciplinaridade?

No verbete do Dicionário de Pedagogia (ARENILLA, 2001), publicado no mesmo ano em que ainda se aprovava obras de Estudos Sociais para uso das escolas no Brasil, interdisciplinaridade é considerada como 
[...] adjetivo: uma questão pode ser interdisciplinar, ou seja, relativa a várias disciplinas.

Pode igualmente ser interdisciplinar a procura do que é comum entre várias disciplinas ou do que o seu confronto pode fazer surgir. Qualquer problema complexo, efetivamente, não pode geralmente ser resolvido, ou mesmo descrito sem o auxílio de disciplinas diferentes, que se revelam complementares. Neste caso, dever-se-ia utilizar preferencialmente a palavra 'pluridisciplinar', que seria mais justa.

Se a comparação de metodologias, e o pôr em evidencia de confrontos possíveis, ou de incompatibilidades que definem as fronteiras de uma disciplina em relação a outra, constituírem o objeto essencial de um trabalho dito interdisciplinar, então a palavra "interdisciplinaridade" é inteiramente conveniente.

Por vezes também se recorre à palavra 'transdisciplinar'. Deveria haver uma significação clara e denominar domínios gerais, estranhos às disciplinas. Os problemas educativos colocados, por exemplo, pelo desenvolvimento dos alunos, pelos seus comportamentos ou resultados, são por natureza 'transdisciplinares'. (ARENILLA, 2001, p. 271).

Para Ivani Fazenda (1994, p. 18), autora de livros sobre o assunto, a interdisciplinaridade surge na Europa, principalmente na França e Itália, em meados da década de 1960, chegando ao Brasil ao final desta mesma década, e "impensadamente tornou-se a semente e o produto das reformas educacionais empreendidas entre 1968 e 1971 (nos três graus de ensino)". Esse fato estreitaria os laços entre interdisciplinaridade e Estudos Sociais, visto que também data desta época a implementação da licenciatura curta de Ciências Sociais e dos Estudos Sociais no ensino fundamental.

A resolução no 2, de 30 de janeiro de 2012, que define Diretrizes Curriculares Nacionais para o Ensino Médio, em seu Art. 4 - XIII sentencia: "a interdisciplinaridade e a contextualização devem assegurar a transversalidade do conhecimento de diferentes componentes curriculares, propiciando a interlocução entre os saberes e os diferentes campos do conhecimento" (BRASIL, 2012, p. 20). 
Entretanto, será que a leitura do prefácio do Guia metodológico para cadernos MEC-HISTÓRIA, publicados em 1969, não propiciaria confusão entre Estudos Sociais e interdisciplinaridade?

Constituem os Estudos Sociais, atividade interdisciplinar, que se processa com a História, a Geografia, Economia e Política, Sociologia e Antropologia Cultural, ciências sociais essas, cujo ensino, ministrado através de metodologia especial, tem por fim realizar valores sociais, exigidos pela época. (SANTOS, 2012, grifo nosso).

Roseli Inês Hickmann organizou um livro denominado Estudos Sociais, outros saberes e outros sabores, $1^{\mathrm{a}}$ edição em 2002, e 2a edição em 2008. A quarta capa assim apresentava a obra:

Este caderno apresenta sugestóes de uma proposta pedagógica interdisciplinar, atraente e significativa, na qual a literatura, a antropologia, as questôes de gênero, a sociologia e outros temas culturais se fazem presentes. A concepção defendida pelos autores é a formação da cidadania do aluno a partir do seu respeito aos diferentes jeitos de ser e de viver do outro no próprio ambiente escolar. (HICKMANN, 2002, grifo nosso).

É provável que o livro trabalhe com o conceito de interdisciplinaridade na forma que está anunciada nas Diretrizes Curriculares Nacionais para o Ensino Médio. O problema é a destinação da obra: Estudos Sociais. Na própria apresentação da autora reforça ainda mais a ideia das ciências sociais e interdisciplinaridade:

O seu enfoque é o de favorecer a construção das identidades socioculturais, formar para a cidadania, para aceitação ao diferente, trabalhando com múltiplos significados das "ciências sociais". Tal currículo pressupóe, assim, trabalhar a realidade social em suas várias dimensóes: temas transversais, globais, planetários, através de um planejamento interdisciplinar e integrado (HICKMANN, 2002, p. 5, grifo nosso). 
Com esses exemplos, pretendeu-se demonstrar que Estudos Sociais, no século XXI, ainda podem ser confundidos com a interdisciplinaridade no meio acadêmico e docente. Essa confusão se deve não somente à subsistência dos Estudos Sociais até recentemente, mas por este ter adquirido uma conotação negativa durante a Ditadura Militar. Este fato representa uma barreira a ser superada para qualquer proposta de formação docente na área de História que trabalhe com interdisciplinaridade.

$\mathrm{Na}$ formação do professor de História torna-se importante a discussão da proposição interdisciplinar, com o aprofundamento do conceito e de formas didáticas de atuação interdisciplinar, porém é fundamental desvincular Estudos Sociais de Interdisciplinaridade, quebrando, assim, o estigma dos Estudos Sociais.

\section{Novas normativas educacionais e interdisciplinaridade}

Desde 1996, quando a nova Lei de Diretrizes de Bases da Educação (LDB) foi sancionada e, sobretudo, a partir do governo Fernando Henrique Cardoso, iniciou-se no Brasil uma restruturação do arcabouço normativo educacional. Ansiado pelos grupos democráticos, a iniciativa parecia como uma luta pelo fim do chamado "entulho democrático", herdado do período ditatorial, mas também e principalmente assumido pelas concepçóes neoliberais que hegemonizaram o período referenciado (OLIVEIRA, 2000).

Nota-se que o conceito de interdisciplinaridade é constante nas novas normativas, embora, ao longo do período, das mudanças governamentais e das revisōes e reedições dos documentos, o conceito seja alterado. Assim, nas Diretrizes Curriculares Nacionais para o Ensino Médio publicadas em 1998, ele aparece no Artigo $8^{\circ}$, ou seja, o que trata da "interdisciplinaridade" nas "escolas":

I - a Interdisciplinaridade, nas suas mais variadas formas, partirá do princípio de que todo conhecimento mantém um diálogo permanente com outros conhecimentos, que pode ser de questionamento, de negação, de complementação, de ampliação, de iluminação de aspectos não distinguidos;

II - o ensino deve ir além da descrição e procurar constituir nos alunos a capacidade de analisar, explicar, prever e intervir, objetivos que são mais facilmente 
alcançáveis se as disciplinas, integradas em áreas de conhecimento, puderem contribuir cada uma com sua especificidade, para o estudo comum de problemas concretos, ou para o desenvolvimento de projetos de investigação e/ou de ação;

III - as disciplinas escolares são recortes das áreas de conhecimentos que representam, carregam sempre um grau de arbitrariedade e não esgotam isoladamente a realidade dos fatos físicos e sociais, devendo buscar entre si interaçôes que permitam aos alunos a compreensão mais ampla da realidade;

IV - a aprendizagem é decisiva para o desenvolvimento dos alunos, e por esta razáo as disciplinas devem ser didaticamente solidárias para atingir esse objetivo, de modo que disciplinas diferentes estimulem competências comuns, e cada disciplina contribua para a constituição de diferentes capacidades, sendo indispensável buscar a complementaridade entre as disciplinas a fim de facilitar aos alunos um desenvolvimento intelectual, social eafetivo mais completo e integrado;

$\mathrm{V}$ - a característica do ensino escolar, tal como indicada no inciso anterior, amplia significativamente a responsabilidade da escola para a constituição de identidades que integram conhecimentos, competências e valores que permitam o exercício pleno da cidadania e a inserção flexível no mundo do trabalho. (BRASIL, 1998, grifo nosso).

É possível perceber que se prevê a interdisciplinaridade nas suas variadas formas, isto é, como princípio organizador dos estudos, como tratamento de temas pelos prismas das diversas disciplinas etc. Assim, avalia Martins (2000, p. 75-76, grifo nosso):

O tema da interdisciplinaridade merece alguma discussão pois não constitui exatamente uma novidade (basta ler a Lei n. 5692/71 e a legislação posterior que a regulamenta). Sobre essa noçáo, presente em muitas propostas curriculares elaboradas a partir dos anos 80 , e sobre os equívocos cometidos em seu nome, muito já se discutiu também (Veiga Neto, 1995). No entanto, é interessante salientar que em seu artigo $8^{\circ}$, a Resolução 
3/98 indica uma concepção de multidisciplinaridade muito mais próxima dos educadores e mais distante de sua definição científica: não se aponta uma integração entre as disciplinas objetivando criar novos conhecimentos, mas sim, o texto explicita apenas a possibilidade de se instaurar um diálogo entre as diferentes disciplinas para troca de experiências e metodologias. Creio que novamente o que a Resoluçáo n. 3/98 pretende por interdisciplinaridade compreende muito mais uma atitude metodológica em relação às disciplinas do currículo, do que propriamente propor uma discussão epistemológica acerca de rupturas de fronteiras e fusão de estudos teóricos entre as diferentes ciências, visando a produção de novos conhecimentos.

Será que encontraríamos nessa avaliação as questões que poderiam nos fazer explicar as tensôes que pensamos existir em nossa análise entre este documento inicial de 1998, a LDB, e todos os outros que a ele se seguem?

É fundamental notar que a autora referencia o Art. 8 - o mesmo que citamos anteriormente - para discutir a interdisciplinaridade, mas que ao fazê-lo introduz o conceito de multidisciplinaridade, apontando, assim entende-se, que o conceito objeto do artigo está sendo trabalhado de forma errada, conforme ela própria indica em outras críticas.

Parece que a tensão está centrada, de fato, entre como a comunidade científica entende o conceito e como os professores o entendem - seja pelo senso comum, seja por divulgaçáo científica (equivocada?) que assim se fez compreender - nas práticas cotidianas na escola.

A reinstalação dos princípios democráticos na sociedade brasileira, no pós-ditadura civil-militar (1964/1985), traz também, por meio dos movimentos sociais, a luta pela democratização da escola em todos os níveis (tanto na ampliaçấo de vagas quanto no papel protagonista de docentes, pais e alunos). A comunidade acadêmica, portanto, apesar de igualmente propulsora deste movimento, teve que começar a enfrentar um "bom problema": exercitar, dentro dos órgãos governamentais e nas escolas, o diálogo sobre como as comunidades escolares e, sobretudo, como os professores incorporam os saberes que circundam (nos cursos de formação continuada, eventos acadêmicos, publicaçôes científicas, publicaçôes de divulgação científica etc.), as suas práticas e problemáticas da tradição escolar. 
Em conjunturas dessa natureza, vivenciam-se novos conflitos, cenários que desafiam a construção do novo. A novidade, evidentemente, não supóe o fim de tudo que está consolidado e estas apropriaçôes não devem ser entendidas, restritamente, como erro ou equívoco da escola, mas como formas de utilização de uma miríade de saberes e práticas que ultrapassam em muito a mera tradução para a educação básica dos saberes científicos, embora os tenham como referência.

É no calor dessa situação de conflito, na acepção de Michel de Certeau (1996), que se entende a afirmação dos Parâmetros Curriculares Nacionais para Ensino Médio, publicado em 2000:

$\mathrm{Na}$ perspectiva escolar, a interdisciplinaridade não tem a pretensão de criar novas disciplinas ou saberes, mas de utilizar os conhecimentos de várias disciplinas para resolver um problema concreto ou compreender um determinado fenômeno sob diferentes pontos de vista. Em suma, a interdisciplinaridade tem uma função instrumental. Trata-se de recorrer a um saber diretamente útil e utilizável para responder às questóes e aos problemas sociais contemporâneos.

$\mathrm{Na}$ proposta de reforma curricular do Ensino Médio, a interdisciplinaridade deve ser compreendida a partir de uma abordagem relacional, em que se propóe que, por meio da prática escolar, sejam estabelecidas interconexóes e passagens entre os conhecimentos através de relaçóes de complementaridade, convergência ou divergência. (BRASIL, 2000a, p. 21).

Nesse documento, é a perspectiva escolar que direciona o conceito, exposto logo para iniciar o parágrafo, e é a utilidade para o ensino-aprendizagem que norteia seu uso, a partir das questóes vivenciadas pela comunidade escolar, aqui citado como "problemas sociais contemporâneos". Embora o fim último seja tratar os conhecimentos, entende-se que apesar de não prever "todas as formas de interdisciplinaridade", como nas Diretrizes Curriculares Nacionais (DCN) de 1998, ainda é a informação (o conteúdo substantivo) que está no centro das preocupaçóes do currículo, referenciado na produção acadêmicocientífica.

Nos PCN + há um novo direcionamento: 
Há habilidades e competências cujo desenvolvimento não se restringe a qualquer tema, por mais amplo que seja, pois implica um domínio conceitual e prático, para além de temas e de disciplinas. A própria competência de dar contexto social e histórico a um conhecimento científico é um exemplo que não está restrito a nenhuma disciplina ou área em particular. O que é preciso compreender é que, precisamente por transcender cada disciplina, o exercício dessas competências e dessas habilidades está presente em todas elas, ainda que com diferentes ênfases e abrangências. Por isso, o caráter interdisciplinar de um currículo escolar não reside nas possíveis associaçóes temáticas entre diferentes disciplinas, que em verdade, para sermos rigorosos, costumam gerar apenas integraçóes e/ou açôes multidisciplinares. O interdisciplinar se obtém por outra via, qual seja, por uma prática docente comum na qual diferentes disciplinas mobilizam, por meio da associação ensino-pesquisa, múltiplos conhecimentos e competências, gerais e particulares, de maneira que cada disciplina dê a sua contribuição para a construção de conhecimentos por parte do educando, com vistas a que o mesmo desenvolva plenamente sua autonomia intelectual. Assim, o fato de diferentes disciplinas trabalharem com temas também diversos não implica a inexistência de trabalho interdisciplinar, desde que competências e habilidades sejam permanentemente mobilizadas no âmbito de uma prática docente, como dissemos acima, centrada na associação ensino-pesquisa. (BRASIL, 2000b).

Nesse documento, os conceitos de competências e habilidades são introduzidos, retirando a ênfase do conteúdo, tema e outras denominaçóes consolidadas no fazer da escola. Além disso, incorpora o saber e o saber-fazer como objetivos comuns e interligados do aprender na escola. Também nega as várias perspectivas de um tema como abordagem interdisciplinar, definindo esta possibilidade como açóes multidisciplinares que não são erros, mas que não devem ser confundidas com a interdisciplinaridade.

Mas isso é importante, não é só uma questão - segundo o documento - de metodologia possível e desejável na escola, mas de concepção do aprendizado na 
escola no sentido de o mesmo nortear-se pela associação ensino-pesquisa. Isso significa, objetivamente, a forma de produção científica - das várias disciplinas - como meio condutor do aprendizado e, dessa forma, levar os educandos a construçấo da autonomia intelectual.

$\mathrm{Na}$ prática, é o questionamento contundente à transmissão do saber centrado no professor e norteado pelas informaçóes consolidadas como concernentes às disciplinas escolares (obrigatoriamente assimiladas pelos alunos) que está em discussão, além da proposição de sua retirada do âmbito da educação básica.

Tratando do mesmo tema, o documento Orientações Curriculares Nacionais, publicado em 2008 (que revisa os Parâmetros Curriculares Nacionais publicados em 2000), parte claramente do PCN + e o amplia:

Para que o princípio pedagógico da interdisciplinaridade possa efetivamente presidir os trabalhos da escola, faz-se necessária uma profunda reestruturaçáodo ponto de vista organizacional, físico-espacial, de pessoal, de laboratórios, de materiais didáticos. Daí o poder estratégico do projeto político-pedagógico da escola como instrumento capaz de mobilizar o conjunto dos profissionais que nela trabalham, assim como a comunidade, para que se possam conseguir as condiçóesque possibilitem implantar as reformas pedagógicas preconizadas. (BRASIL, 2008, p. 69).

A defesa da interdisciplinaridade e de outras competências e habilidades alcança nesse documento uma maturidade propositiva, dentro dos princípios de uma sociedade democrática. Reconhece todas as contribuiçóes acadêmicocientíficas, mas também a tradição escolar e as necessidades do "chão da escola", indica a necessidade de revisão da prática docente e assevera a necessidade pari passu de reestruturar o tempo da escola ainda baseado no tempo fabril e de equipamentos que auxiliem essa nova estrutura. Isso é muito diferente das afirmações sobre a necessidade de docentes reverem suas concepçóes de ciência e/ou a boa vontade para mudar sua prática. Debates instituídos ao longo de anos e de publicações representam ganhos da sociedade democrática.

As novas Diretrizes Curriculares Nacionais para o Ensino Médio, por exemplo, publicadas em 2011 afirmam: 
Art. 7o A organização curricular do Ensino Médio tem uma base nacional comum e uma parte diversificada que não devem constituir blocos distintos, mas um todo integrado, de modo a garantir tanto conhecimentos e saberes comuns necessários a todos os estudantes, quanto uma formaçáo que considere a diversidade e as características locais e especificidades regionais.

Art. $8^{\circ} \mathrm{O}$ currículo é organizado em áreas de conhecimento, a saber:

I - Linguagens;

II - Matemática;

III - Ciências da Natureza;

IV - Ciências Humanas.

$\$ 1^{\circ} \mathrm{O}$ currículo deve contemplar as quatro áreas do conhecimento, com tratamento metodológico que evidencie a contextualização e a interdisciplinaridade ou outras formas de interação e articulação entre diferentes campos de saberes específicos.

$\$ 2^{\circ}$ A organização por áreas de conhecimento não dilui nem exclui componentes curriculares com especificidades e saberes próprios construídos e sistematizados, mas implica no fortalecimento das relaçóes entre eles e a sua contextualização para apreensão e intervenção na realidade, requerendo planejamento e execução conjugados e cooperativos dos seus professores. (BRASIL, 2013, p. 196-197).

Neste documento é clara a determinação que o tratamento por área de conhecimento náo exclui o conhecimento disciplinar, tampouco as disciplinas. Contudo, todas as vezes que o conhecimento por áreas é referido em algum documento legal, logo se recupera (no caso da disciplina História) a experiência dos Estudos Sociais e, portanto, a afirmativa de que está se defendendo a exclusão da mesma, sobretudo, o fim da possibilidade de aprendizagem do espírito crítico pelos alunos.

\section{Considerações finais}

Na primeira parte deste texto, foi historiada a associação interdisciplinaridade e Estudos Sociais e é notório o trauma social instaurado pela ditadura no que 
diz respeito à intervenção no ensino-aprendizagem escolar e, nesse sentido, não é necessário explaná-lo novamente. Porém, reconhecendo que o currículo é uma evidência também das realidades históricas das sociedades, não é possível começar a evidenciar possíveis consensos e pautar novos itens nesse debate?

A reiterada assertiva sobre o desinteresse dos alunos pela História, os indicativos das pesquisas sobre a inexistência de progressóes, para além do tamanho do texto e quantidade de informaçôes nos livros didáticos de História (FREITAS, 2011a, 2011b), as condições de planejamento e fechamento de carga horária dos professores da educação básica, não seriam elementos suficientes para demonstrar a necessidade de deixarmos um posicionamento defensivo e adotarmos um propositivo?

$\mathrm{Na}$ medida em que toda política de currículo é uma política cultual, tanto sua análise a partir da derivação dos processos econômicos e de classe, nos quais o Estado está inegavelmente engendrado, quanto seu deslocamento fetichizado dessas relaçôes exclui dimensóes importantes das lutas sociais para dar sentido a algumas dinâmicas da cultura e, particularmente, do conhecimento. (LOPES, 2006, p 37).

Enquanto denunciamos as perdas da disciplina História, Programas como o Ensino Médio Inovador e exames em larga escala como o ENEM induzem as mudanças preconizadas, articulando-as com o reordenamento jurídico que, a cada dia, se amplia:

O Programa Ensino Médio Inovador (ProEMI) estabelece em seu Documento Base um referencial de tratamento curricular, indicando as condiçôes básicas para implantação do Projeto de Redesenho Curricular (PRC).

a) Carga horária mínima de 3.000 (três mil horas), entendendo-se 2.400 horas obrigatórias, acrescidas de 600 horas a serem implantadas de forma gradativa;

b) Foco em açóes elaboradas a partir das áreas de conhecimento, conforme proposto nas Diretrizes Curriculares Nacionais para o Ensino Médio e que são orientadoras das avaliaçôes do ENEM;

c) Açôes que articulem os conhecimentos à vida dos estudantes, seus contextos e realidades, a fim de atender 
suas necessidades e expectativas, considerando as especificidades daqueles que são trabalhadores, tanto urbanos como do campo, de comunidades quilombolas, indígenas, dentre outras;

d) Foco na leitura e letramento como elementos de interpretação e de ampliação da visão de mundo, basilar para todas as áreas do conhecimento;

e) Atividades teórico-práticas que fundamentem os processos de iniciação científica e de pesquisa, utilizando laboratórios das ciências da natureza, das ciências humanas, das linguagens, de matemática e outros espaços que potencializem aprendizagens nas diferentes áreas do conhecimento;

f) Atividades em Línguas Estrangeiras/Adicionais, desenvolvidas em ambientes que utilizem recursos e tecnologias que contribuam para a aprendizagem dos estudantes;

g) Fomento às atividades de produção artística que promovam a ampliaçáo do universo cultural dos estudantes; h) Fomento as atividades esportivas e corporais que promovam o desenvolvimento integral dos estudantes;

i) Fomento às atividades que envolvam comunicaçáo, cultura digital e uso de mídias e tecnologias, em todas as áreas do conhecimento;

j) Oferta de açóes que poderão estar estruturadas em práticas pedagógicas multi ou interdisciplinares, articulando conteúdos de diferentes componentes curriculares de uma ou mais áreas do conhecimento;

k)Estímulo à atividade docente em dedicação integral à escola, com tempo efetivo para atividades de planejamento pedagógico, individuais e coletivas;

1) Consonância com as açôes do Projeto PolíticoPedagógico implementado com participação efetiva da Comunidade Escolar;

m) Participação dos estudantes no Exame Nacional do Ensino Médio (ENEM);

n) Todas as mudanças curriculares deverão atender às normas e aos prazos definidos pelos Conselhos Estaduais para que as alterações sejam realizadas. (BRASIL, 2009, p. 11-12, grifos nosso). 
O Programa Ensino Médio Inovador, por exemplo, incentiva o redesenho curricular, assim afirma o seu documento orientador para as escolas que querem se candidatar a sediar. Nos itens b, e, i e k grifados explicitam a presença das concepçóes analisadas e as induzem por meio dos incentivos que o PROEMI assegura.

A lógica e o tempo das políticas governamentais e da escola ultrapassam as discussões acadêmicas e científicas. Isso não se constitui em características positivas ou negativas, apenas explicitam as diferenças dos espaços. Mas, como formadores de professores e cidadáos imersos nas disputas sociais, aos professores universitários de História, fazem-se necessárias tomadas de posiçóes que considerem a complexidade do momento político, econômico, cultural e social que vivemos. O passado nos informa e nos orienta, mas náo deve limitar nossa ousadia na construção do novo.

\section{REFERÊNCIAS}

AGUAYO, Alfredo Miguel. Didática da Escola Nova. 9. ed. São Paulo: Companhia Editora Nacional, 1954.

ARÉNILLA, Louis; GOSSOT, Bernard; ROLLAND, Marie-Claire. Dicionário de Pedagogia. Lisboa: Instituto Piaget, 2001.

BRASIL. Lei n ${ }^{\circ}$ 4.024, de 20 de dezembro de 1961. Fixa as Diretrizes e Bases da Educação Nacional. Diário Oficial da União, Brasília, DF, 27 dez. 1961. Disponível em: <http://www.planalto.gov.br/ccivil_03/leis/14024.htm>.

BRASIL. Decreto Lei no 547, de 18 de abril de 1969. Autoriza a organização e o funcionamento de cursos profissionais superiores de curta duração.

Diário Oficial da União, Brasília, DF, 22 abr. 1969. Disponível em: <http:// www.planalto.gov.br/ccivil_03/decreto-lei/1965-1988/Del0547.htm>.

BRASIL. Conselho Nacional de Educação. Resolução n 3, de 26 de junho 1998. Define Diretrizes Curriculares Nacionais para o Ensino Médio. Diário Oficial da União, Brasília, DF, 5 ago 1998.

BRASIL. Ministério da Educação. Secretaria de Educação Média e Tecnologia. Parâmetros Curriculares Nacionais: ensino médio: bases legais. Brasília, DF: 2000a. 
BRASIL. Ministério da Educação. Secretaria de Educação Média e Tecnologia. Parâmetros Curriculares Nacionais +: orientaçóes educacionais complementares aos Parâmetros Curriculares Nacionais. Brasília, DF: 2000b.

BRASIL. Ministério da Educação. Secretaria de Educaçáo Básica. Orientações Curriculares para o ensino médio. Brasília, DF: MEC/SEB, 2008. v. 3.

BRASIL. Ministério da Educação. Secretaria de Educação Básica. Programa Ensino médio inovador: documento orientador. Brasília, DF: MEC/SEB, 2009.

BRASIL. Conselho Nacional de Educação. Câmara de Educação Básica. Resolução no 2, de 30 de janeiro de 2012. Define Diretrizes Curriculares Nacionais para o Ensino Médio. Diário Oficial da União, Brasília, DF, 31 de janeiro de 2012.

BRASIL. Ministério da Educação. Secretaria de Educação Básica. Diretoria de Currículos e Educação Integral. Diretrizes Curriculares Nacionais da Educação Básica. Brasília, DF: MEC/SEB, 2013.

CORREIA FILHO, Virgílio. O ensino primário no Brasil. In: REIS, Artur César Ferreira et al. O ensino da história no Brasil. México: Instituto Panamericano de Geografia e História, 1953.

CERTEAU, Michel de. A invenção do cotidiano. Petrópolis: Vozes, 1996.

FAZENDA, Ivani C. A. Interdisciplinaridade: história, teoria e pesquisa. Campinas, SP: Papirus, 1994.

FERNANDES, Antonia Terra de Calazans. Livros Didáticos e a integração da vida social e natural. In: SIMPÓSIO NACIONAL DE HISTÓRIA, 25., 2009, Fortaleza. Anais ANPUH... Fortaleza: ANPUH, 2009. Disponível em: $<$ http://anpuh.org/anais/?p=18791>.

FREITAS, Itamar. Conteúdos e progressão dos conteúdos no ensino de História (2): a contribuição dos teóricos do desenvolvimento (Jean Piaget). Ensinar e Aprender História, 9 jan. 2011 a. <http://itamarfo.blogspot. com/2011/01/conteudos-e-progressao-dos-conteudos-no_09.html>. 
FREITAS, Itamar. Perspectivas desenvolvimentais, aprendizagem e possibilidades de progressão a partir da obra de Jerome Bruner. Ensinar e Aprender História, 4 mar. 2011b. Disponível em: <http://itamarfo.blogspot. com/2011/03/perspectivas-desenvolvimentais.html>.

GUIA de Livros Didáticos 1a a 4a séries: PNLD 2001/2002. Brasília: MEC/ SEF, 2000.

HICKMANN, Roseli Inês (Org.). Estudos Sociais, outros saberes e outros sabores. 2. ed. Porto Alegre: Mediação, 2008.

HOLLANDA, Guy de. Programas e compêndios de história para o ensino secundário brasileiro, 1931-1956. Rio de Janeiro: MEC/INEP/Centro Brasileiro de Pesquisas educacionais, 1957.

JOHNSON, Henry. Report of the Commission on the Social Studies: an introduction to the History of the Social Sciences in schools. New York: Charles Scribner's Sons, 1932.

LOPES, Alice Casimiro. Discursos nas políticas de currículo. Currículo sem Fronteiras, [S.I.], v. 6, n. 2, 2006.

LOURENÇO FILHO, Manoel B. Introdução ao Estudo da Escola Nova: bases, sistemas e diretrizes da pedagogia contemporânea. 14. ed. Rio de Janeiro: EdUERJ, 2002.

MARTINS, Ângela Maria. Diretrizes Curriculares Nacionais para o Ensino Médio: avaliação de documento. Cadernos de Pesquisa, São Paulo, n. 109, mar. 2000.

MATE, Cecília Hanna. Lourenço Filho e a Reforma de 1931 (SP): o governo de professores e de alunos. In: MIGUEL, Elisabeth Blancketall (Org.). Reformas educacionais, as manifestaçóes da Escola Nova no Brasil (1920-1946). Campinas, SP: Autores Associados; Uberlândia, MG: EDUFU, 2011.

NADAI, Elza. Estudos Sociais no primeiro grau. Em Aberto, Brasília, v. 7, n. 37, jan./mar. 1988.

OEA. Organização de los Estados Americanos. La renovacion de la enseñanza de las ciencias sociales em las escuelas secundarias de los Estados Unidos.

Washington: Departamento de Assuntos Educativos, Union Panamericana, Organización de los Estados Americanos, 1968. 
OLIVEIRA, Margarida Maria Dias de (Org.). Contra o consenso: LDB, DCN, PCN e reformas no ensino. João Pessoa: Sal da Terra, 2000.

OLIVEIRA, Maria Helena Cozzolino de; MONTEIRO, Ieda da Silva. Didática dos Estudos Sociais: como aprender, como ensinar. 6. ed. São Paulo: Saraiva, 1992.

SANTOS, Beatriz Boclin Marques dos. A abordagem historiográfica da disciplina escolar Estudos Sociais nas décadas de 1960 e 1970: nova perspectiva histórica. In: ENCONTRO REGIONAL DE HISTÓRIA DA ANPUH-RIO, 15., 2012, Rio de Janeiro. Anais do XV Encontro Regional da ANPUH-Rio. Rio de Janeiro: ANPUH, 2012. Disponível em: <http://www. encontro2012.rj.anpuh.org/resources/anais/15/1338480525_ARQUIVO_ artigo_Anpuh_2012.pdf>. Acesso em: 22 mar. 2014.

ZANTEN, Agnès Van (Coord.). Dicionário de Educação. Petrópolis, RJ: Vozes, 2011. 


\section{Politiques et pratiques de I'histoire scolaire dans I'enseignement secondaire du Brèsil: I’interdisciplinarité en debate}

\section{Résumé}

La question de l'interdisciplinarité est une nouvelle et spécifique demande que se pose pour la formation des enseignants. Comment, alors, l'appliquer dans l'Histoire et la Géographie quand sont elles confondues avec les anciennes Études Sociales? Ce text prétend démontrer l'introduction de la proposition des Études Sociales, par l'intermède de l'École Nouvelle, et de son ultérieure permanence dans l'éducation brésilienne pendant le XX siècle. Après, il présente et discute l'approche de l'interdisciplinarité dans les documents que orientent l'enseignement secondaire au Brésil, entre 1998 et 2013. Pour cela, il analise la bibliographie et les documents officiels que orientent la question et, à partir de ceux-ci, proposer quelques hypothèses sur la conflictuelle discussion sur l'insertion de l'interdisciplinarité dans l'éducation de base, si bien qu'elle soit largement défendue dans l'académie.

Mots-clés: Enseignement de l'histoire. Interdisciplinarité. Enseignement Secondaire.

\section{History's policies and practices in Brazilian High School: interdisciplinarity in debate}

\section{Abstract}

The question of interdisciplinarity is a new and specific demand that arises for teacher training. How, then, make it effective in the areas of History and Geography, when they are confused with the old Social Studies? This paper aims to demonstrate the introduction of the proposal of Social Studies, by the New School Movement, and his subsequent adoption by Brazilian education during the twentieth century. Then, it is presented and discussed the interdisciplinary approach of the documents that guide high school in Brazil between 1998 and 2013. For this end, we analyze the literature and official documents that reference the issue and from this subject on, we had developed some hypotheses for so conflicted, although widely held by academics, discussion on the inclusion of interdisciplinarity in basic education.

Keywords: History teaching. Interdisciplinarity. High school. 
Políticas e práticas da história escolar no ensino médio do Brasil: a interdisciplinaridade em debate 451

\section{Margarida Maria Dias de Oliveira}

E-mail:margaridahistoria@yahoo.com.br

Maria Inês Sucupira Stamatto

E-mail:stamattoines@gmail.com

\section{Itamar Freitas}

E-mail: itamarfo@gmail.com

Recebido em: 15/2/2014

Versão Final recebida em: 26/3/2014

Aprovado em: 30/3/2014 